\title{
Reevaluating the potency of the memory conformity effect
}

\author{
Glen E. Bodner, Elisabeth Musch, and Tanjeem AZad \\ University of Calgary, Calgary, Alberta, Canada
}

\begin{abstract}
Witnesses sometimes report event details that are acquired solely from another witness. We reevaluated the potency of this memory conformity effect. After viewing a crime video, some participants learned about nonwitnessed details via discussion (dyad group), reading another participant's report (read group), or watching another version of the video (both-video group). In Experiment 1, these participants often reported nonwitnessed details, but on a source-judgment test most details were attributed primarily to the actual source rather than to the video. In addition, the dyad group was not more likely than the read or both-video groups to report nonwitnessed details. Participants in Experiment 2 were explicitly discouraged from providing details that were remembered from the secondary source only. These postwarning instructions substantially reduced the memory conformity effect, and a dyad group was not more likely than a read group to report nonwitnessed details. Encouraging source monitoring at test can reduce the negative consequences of co-witness collaboration.
\end{abstract}

We examined how likely it is that witnesses who learn about certain crime event details solely from another witness will later come to report-and believe-that they saw those details (see, e.g., Lindsay \& Johnson, 1989; Zaragoza \& Koshmider, 1989; Zaragoza \& Lane, 1994). Misinformation effects occur when misleading information about a witnessed event decreases the accuracy of reports about details of that event. The occurrence of these effects is well documented in the eyewitness memory literature (for reviews, see Ayers \& Reder, 1998; Pickrell, Bernstein, \& Loftus, 2004). In addition to distorting what is reported about witnessed details, misinformation can lead witnesses to report nonwitnessed details. For example, after participants viewed a film of a car accident, Loftus and Palmer (1974) asked them leading questions that not only influenced estimates of the car's speed but also led many to report having seen broken glass that was not shown in the film. Research on misinformation effects has implications for memory theorizing (e.g., understanding the mechanisms that produce memory inaccuracies) and real-world applications (e.g., understanding the factors that influence eyewitness reliability).

Misinformation about an event is typically presented in one of three ways (Wright, Self, \& Justice, 2000): (1) leading questions (see, e.g., Loftus, Miller, \& Burns, 1978; Loftus \& Palmer, 1974), (2) an event narrative, witness report, or media report (see, e.g., Betz, Skowronski, \& Ostrom, 1996; Hoffman, Granhag, Kwong See, \& Loftus, 2001; Luus \& Wells, 1994; Meade \& Roediger, 2002; Shaw, Garven, \& Wood, 1997), or (3) an interaction with another person (see, e.g., Gabbert, Memon, \& Allan, 2003; Gabbert, Memon, Allan, \& Wright, 2004;
Gabbert, Memon, \& Wright, 2006, 2007; Hope, Ost, Gabbert, Healey, \& Lenton, 2008; Meade \& Roediger, 2002; Ost, Ghonouie, Cook, \& Vrij, 2008; Paterson \& Kemp, 2006a; Reysen, 2003, 2005; Roediger, Meade, \& Bergman, 2001; Schneider \& Watkins, 1996; Shaw et al., 1997; Wright et al., 2000). This last means is perhaps the one that is most likely to occur in real life, and the misinformation effect that arises in co-witness situations has been termed a memory conformity effect (Wright et al., 2000).

In an early study of memory conformity, Wright et al. (2000) showed pairs of participants (dyads) a series of photos depicting a wallet theft. The photos were identical except that one dyad member saw a photo of the thief standing alone, whereas the other saw a photo of the thief with an accomplice. Ninety-eight percent of participants were initially accurate when asked independently whether the thief had an accomplice. After dyads had discussed whether the thief was alone, however, $79 \%$ of them came to an agreement. In most pairs, then, one dyad member conformed to the other's report.

Inspired by this study, Gabbert et al. (2003) developed a paradigm in which each member of a given pair of participants watched a video of the same crime event, but each saw the event filmed from a different camera angle. Each version contained two critical details that could not be seen in the other version, but participants were allowed to believe that they and their partner had seen the same video. Dyads collaboratively filled out an initial questionnaire about the event, and each member then completed the main questionnaire independently. On the main questionnaire, $71 \%$ of the dyad members reported at least one of

G. E. Bodner, bodner@ucalgary.ca 
the critical nonwitnessed details. In contrast, participants in a control group who completed both questionnaires alone and who were not exposed to any misinformation never reported nonwitnessed details.

Gabbert et al. (2003) attributed their memory conformity effect to the confusion of participants about the source of their memories (see, e.g., Johnson, Hashtroudi, \& Lindsay, 1993; Zaragoza \& Lane, 1994), as well as to social influences such as the desire to cooperate and to appear accurate (see, e.g., Deutsch \& Gerard, 1955). Given that co-witnesses often discuss crime events (Paterson \& Kemp, 2006b; Skagerberg \& Wright, 2008), this effect has important implications regarding the reliability of eyewitness memory. The origin of the effect could not be isolated in this study, however, because only the dyad group received misinformation.

Other studies have examined the potency of social interaction relative to other means of receiving misinformation. After participants viewed photos of household scenes, Meade and Roediger (2002) had either an actual confederate or a virtual confederate (who ostensibly presented a previous participant's responses) provide misinformation about objects that had been shown in the scenes. On a cued-recall test, the two groups were equally likely to report nonwitnessed objects; but on a sourcemonitoring task, the actual group was more likely to claim that they had seen the nonwitnessed objects in the slides. After participants watched an enacted video of a theft, Gabbert et al. (2004) found that nonwitnessed details that had been provided via discussion with a confederate were more likely to be reported than were details that had been read in a narrative report that was ostensibly provided by a previous participant. Finally, Paterson and Kemp (2006a) compared four methods of receiving misinformation about a video of a theft: leading questions, reading of a fictitious media report, reading of and agreement or disagreement with statements that were ostensibly written by other people, and collaboration with a confederate. A control group that was not exposed to misinformation was also tested. On a free-recall test, the dyad group reported more nonwitnessed details than did all other groups except the media-report group. Participants were not instructed to report only details that they had witnessed personally, however. Participants may therefore have knowingly reported nonwitnessed details.

Researchers have begun to focus on the factors that influence memory conformity - such as the characteristics of the discussion (Gabbert et al., 2006), how long dyad members think each member spent encoding the event (Gabbert et al., 2007), and the relationship between the dyad members (Hope et al., 2008) - without including non-dyad comparison groups. The exclusive focus on dyads is justifiable from an applied perspective, but it does not contribute to our ability to assess the potency or origin of these effects. In the present article, we report two experiments that were designed to extend Gabbert et al.'s (2003) paradigm in order to help assess these issues.

Our primary goal was to examine whether dyads who report nonwitnessed details believe, versus merely report, having seem them in the video (see, e.g., Lindsay \&
Johnson, 1989; Zaragoza \& Koshmider, 1989; Zaragoza \& Lane, 1994). Gabbert et al.'s (2003) dyads were instructed to "think back to the video" when responding, but they were not specifically asked to respond on the basis of only that which they saw. And Paterson and Kemp's (2006a) participants were simply instructed to recall as much as they could about the crime video. Participants in both studies may therefore have included details that they had knowingly obtained from their partner-because they were not spontaneously evaluating the source of their memories - in order to please the experimenter (i.e., a normative influence) and/or to try to be as accurate as possible (i.e., an informational influence). We used two approaches to examine these possibilities, as Gabbert et al. (2004) recommended:

The extent to which co-witnesses can disregard, i.e. exclude, socially (vs. nonsocially) encountered misinformation would be worth exploring. This could be achieved by giving witnesses source-monitoring instructions, warning them (at test) that the misinformation was in fact errant, and should be withheld or indicated as such in their recall ... this seems, to us, to be a worthwhile goal also from the forensic point of view, where the issue of how to distinguish between true and false corroboration between witness reports has considerable weight. (p. 225, italics added)

In Experiment 1, participants completed a main questionnaire (to establish the usual memory conformity effect), reread their cued-recall responses, and then made a source judgment. Specifically, they judged whether each answer was based primarily on what they saw in the video versus on what they learned from the secondary source. Only participants who believed that they had seen the nonwitnessed details should have attributed their answers primarily to the video. Source judgments have been found to reduce or even eliminate other misinformation effects (see, e.g., Lindsay \& Johnson, 1989; Zaragoza \& Koshmider, 1989). Furthermore, Gabbert and colleagues (Gabbert et al., 2003; Gabbert et al., 2004; Gabbert et al., 2007) acknowledged that memory conformity might result in part from source confusion rather than from social influences. Our source-judgment test thus provided a means of evaluating this possibility.

Experiment 2 took a different approach to gauging the potency of memory conformity. After completing the main questionnaire, participants here received explicit postwarning instructions to not report details that they had acquired from the secondary source unless they also remembered seeing those details (Lindsay, 1990). Prior studies have shown that postwarning instructions can reduce misinformation effects (e.g., Chambers \& Zaragoza, 2001) by encouraging participants to monitor the sources and characteristics of their memories more thoroughly, rather than simply inducing a more conservative response bias (e.g., Echterhoff, Hirst, \& Hussy, 2005). Postwarning instructions should also help participants avoid succumbing to any normative or informational pressures: Participants should report only nonwitnessed details that they feel they saw. 
Our study also reinvestigated whether social interaction with a co-witness is an especially potent source of misinformation. To this end, Experiments 1 and 2 also included a read group in which participants were exposed to misinformation when they read the initial questionnaire responses of another actual participant (cf. Gabbert et al., 2004; Meade \& Roediger, 2002; Paterson \& Kemp, 2006a) who had seen the other version of the video. The read group differed from the dyad group chiefly in that participants were not exposed to nonwitnessed details via interactive discussion with the other participant. The presence of a live partner in the read group is arguably more similar to the dyad condition than is the reading of a narrative that was ostensibly written by another participant. To the extent that interactive discussion was the locus of Gabbert et al.'s (2003) memory conformity effect, the dyad group should have reported more nonwitnessed details than did the read group. In Experiment 1, we also included a both-video group in which participants watched the second version of the video immediately after watching the first version. At test, this group was asked to respond on the basis of only that which they had seen in the first video. We expected the viewing of both videos to produce substantial source-monitoring difficulty given the similarity of the two sources (Lindsay, 1990); thus, the both-video group provided another benchmark for evaluating the effects that were obtained in the dyad and read groups.

\section{EXPERIMENT 1}

Experiment 1 reevaluated the potency of the memory conformity effect in two ways. First, after participants had recalled the event, a source-judgment test asked them to attribute the nonwitnessed details that they had reported either primarily to the video or primarily to the actual secondary source. We expected that participants would sometimes report nonwitnessed details that they would later correctly attribute to the secondary source (see, e.g., Lindsay \& Johnson, 1989; Zaragoza \& Koshmider, 1989). Second, we compared a dyad group against groups who had received misinformation either by reading another participant's report (read group) or by viewing both versions of the video (both-video group). A control group was also tested.

\section{Method}

Participants. Undergraduate psychology students, 120 in all, from the University of Calgary participated for course credit. They were randomly assigned to the dyad group (40 participants, 20 pairs), the read group (40 participants, 20 pairs), the both-video group (20 participants), or the control group (20 participants). During collaboration, five dyads suspected that they had watched different videos; they were replaced. No participants guessed the study's purpose when asked to write it down after the study. Five dyad group participants and 1 read group participant were not exposed to either of the critical nonwitnessed details. They were excluded from further analysis, leaving 35 participants in the dyad group and 39 in the read group.

Simulated crime-event videos. Participants viewed one of the two 1.5-min videos from Gabbert et al. (2003). The videos feature a simulated crime event in which a young woman enters an unoc- cupied office to return a book and then commits a theft. Both versions show the same sequence of events, but each was filmed from a different camera angle (from inside the office vs. from outside the door), so that each version contains a different pair of critical details that cannot be seen in the other version. One version shows the title of the book and the woman throwing a note into a garbage can; the other shows the woman looking at her watch and pocketing money from a wallet that she finds in a desk drawer. The digitized clips were viewed on a computer monitor.

Testing procedure. The initial portions of the testing procedure followed that of Gabbert et al. (2003). Dyad and read groups were tested in pairs of participants who arrived at the laboratory at the same appointment time; both-video and control participants were tested individually. Participants viewed one version of the video in one of two adjacent private testing rooms, ostensibly so that they could each sit directly in front of a monitor. Dyad and read pairs watched different versions of the event, and both members were allowed to assume that they had watched the same video. In the control group, the version of the video was counterbalanced across participants. In the both-video group, the order in which the two versions were watched was counterbalanced across participants.

All participants were then asked to imagine that they had actually witnessed the event. They completed an initial questionnaire that was described as an opportunity to sort through their memories of the event before the arrival of the police. They reported the witnessed sequence of actions and events as thoroughly and accurately as possible, and they then answered seven questions that were designed to elicit reports of the critical details. Dyads were asked to discuss the event and to provide the most accurate collaborative notes possible. One member of the dyad typed their responses into a form. Participants in the other groups typed their responses into a form on their own. The read group pairs then switched adjacent rooms (walking past each other in the process) and read each other's responses at their own pace; they then returned to their original rooms. All participants then performed an unrelated 5-min filler task.

The main questionnaire was then completed individually. Gabbert et al.'s (2003) instructions were used: Participants were again instructed to "think back to the video" that they had watched ("first video" was specified for the both-video group) and to answer the questions as if they had witnessed the scene and were now providing information for the police. The main questionnaire again began with a free recall of the sequence of actions and events, and it was followed by a mixture of four critical questions and four neutral questions about specific aspects of the event. Each critical question was designed to elicit a report of a critical detail (two witnessed, two nonwitnessed). Participants typed their responses into a form and rated their confidence in each response on a 7-point Likert scale $(1=$ not very confident, $7=$ very confident $)$.

At this point, we departed from Gabbert et al.'s (2003) procedure by introducing a source-judgment task. Participants (except for those in the control group) reviewed each answer in turn and judged which of the two memory sources had contributed more to their answer. Specifically, they indicated whether each answer was based more strongly on (1) what they had seen in the original video, or (2) the discussion with their partner (dyad group), their partner's questionnaire answers (read group), or the second video (both-video group).

Scoring procedure. Two blind raters independently coded each detail that was reported in the free-recall and/or specific-question part of the second questionnaire as correct, critical, or incorrect. Correct details were scored using a list of 35 details that were common to both videos. Mention of a given detail was counted only once. Disagreements were rare, and they were resolved through discussion.

\section{Results}

The results were significant at the .05 level except as otherwise indicated. 
Table 1

Percentage of Participants Reporting One or Both Critical Nonwitnessed Details, and Their

Attribution of the Primary Source for Those Details

\begin{tabular}{cccc}
\hline & & \multicolumn{2}{c}{ Primary Source Attribution (\%) } \\
\cline { 3 - 4 } Group & $\begin{array}{c}\text { One or } \\
\text { Both (\%) }\end{array}$ & $\begin{array}{c}\text { Secondhand } \\
\text { Source (Correct) }\end{array}$ & $\begin{array}{c}\text { Video Source } \\
\text { (Incorrect) }\end{array}$ \\
\hline Experiment 1 & & & \\
Both video & 100 & 45 & 25 \\
Dyad & 74 & 49 & 14 \\
Read & 64 & 33 & 15 \\
Control & 10 & - & - \\
Experiment 2 & & - & - \\
Dyad & 34 & - & - \\
Read & 28 & - & \\
\hline
\end{tabular}

Reporting of nonwitnessed details. Table 1 shows the percentage of each group that reported one or both critical nonwitnessed details (in the both-video group, nonwitnessed refers to critical details in the second video). Two control group participants inferred a nonwitnessed detail. The chi-square analysis that was used by Gabbert et al. (2003) indicated a significant association between group and the number of participants reporting at least one nonwitnessed detail $\left[\chi^{2}(3, N=114)=38.19\right]$. The dyad group was not significantly more likely to report nonwitnessed details than was the read group (74\% vs. $64 \%)\left[\chi^{2}(1, N=74)=0.89, p=.45\right]$. The dyad group was more likely to report nonwitnessed details than was the control group $(10 \%)\left[\chi^{2}(1, N=55)=21.05\right]$, as was the read group $\left[\chi^{2}(1, N=59)=15.59\right]$, but the bothvideo group $(100 \%)$ was more likely to do so than both the dyad group $\left[\chi^{2}(1, N=55)=6.15\right]$ and the read group $\left[\chi^{2}(1, N=59)=9.41\right]$.

The similarity of the conformity rates in the dyad and read groups did not result from exposure to different numbers of nonwitnessed details on average (1.54 vs. 1.69) $[t(1,72)=1.32, S E=0.11, p=.19]$. To better control for this possibility, however, we also divided the number of nonwitnessed details that a participant reported by the number to which that participant had been exposed. This misinformation index was higher in the dyad group than in the read group (.66 vs. .49), but this difference did not reach significance $[t(1,72)=1.62$, $S E=0.11, p=.11]$.

We also compared confidence ratings in reports of critical details in the dyad and read groups as a function of whether the details were witnessed or nonwitnessed (Table 2). Higher confidence ratings were given when critical details were witnessed versus when they were not (5.9 vs. 4.1). The dyad group was more confident than the read group overall (5.4 vs. 4.6) $\left[F(1,37)=5.77, M S_{\mathrm{e}}=2.40\right]$, but not especially so for nonwitnessed details $(F<1$ for the interaction).

Memory accuracy. As can be seen in Table 3, there was no difference across groups in the number of accurate details that were reported $(F<1)$, nor in the number of incorrect details that participants reported $[F(3,110)=$ $\left.1.81, M S_{\mathrm{e}}=1.63, p=.15\right]$. As in Gabbert et al. (2003) and Gabbert et al. (2007), there was also no relationship between the number of accurate details that were reported and whether a participant reported nonwitnessed details $\left[r_{\mathrm{pb}}(110)=.03, p=.73\right]$; thus, the differences in reporting of nonwitnessed details across the groups were likely not the result of differences in memory accuracy or response bias.

Source-monitoring judgments. Source judgments were provided by the three experimental groups for their responses to the cued-recall portion of the questionnaire only. As is shown in Table 1, the experimental groups showed a similar tendency to attribute the nonwitnessed details that they reported primarily to the correct secondary source rather than to the (first) video $\left[\chi^{2}(2, N=94)=\right.$ $1.16, p=.56]$.

\section{Discussion}

We replicated the large memory conformity effect in a dyad group relative to a control group that was reported by Gabbert et al. (2003). Dyad members were far more likely than control members to report nonwitnessed details in their study ( $71 \%$ vs. $0 \%)$ and in ours $(74 \%$ vs. $10 \%$ ); however, three pieces of evidence suggest that these rates overstate the potency of collaboration effects. First, the dyad group was not more likely to report nonwitnessed details than was a read group who obtained these details by reading another live participant's report. Second, the rate of reporting critical details that had been obtained from a secondary source was greater in the both-video group than in either the dyad or the read group. Third, on a postrecall source-judgment task, participants attributed the majority of the nonwitnessed details that they reported primarily to the correct secondary source rather than to the incorrect video source. Indeed, although $63 \%$ of the dyad group reported at least one nonwitnessed detail in response to a specific question, only $14 \%$ later attributed these responses primarily to the video. As in the standard misinformation paradigm (e.g., Lindsay \& Johnson, 1989; Zaragoza \& Koshmider, 1989), therefore, participants who report nonwitnessed details may conclude, upon querying of the source of their memories, that they did not obtain those details primarily from the event itself.

Table 2

Confidence Ratings (Means and Standard Errors) in Reported Witnessed Versus Nonwitnessed Critical Details

\begin{tabular}{llllll}
\hline & \multicolumn{4}{c}{ Critical Detail Type } \\
\cline { 5 - 6 } & \multicolumn{3}{c}{ Witnessed } & & \multicolumn{3}{c}{ Nonwitnessed } \\
\cline { 6 - 6 } \cline { 5 - 6 } Group & $M$ & $S E$ & & $M$ & $S E$ \\
\hline Experiment 1 & & & & \\
$\quad$ Dyad & 6.2 & 0.3 & & 4.7 & 0.4 \\
$\quad$ Read & 5.6 & 0.3 & & 3.5 & 0.4 \\
Experiment 2 & & & & \\
$\quad$ Dyad & 6.1 & 0.3 & & 5.4 & 0.5 \\
$\quad$ Read & 6.2 & 0.3 & & 5.2 & 0.4 \\
\hline
\end{tabular}

Note-Scale was $1=$ not at all confident, $7=$ very confident . Experiment 1 means are based on 21 dyad and 18 read participants, all of whom reported and rated their confidence in at least one witnessed and one nonwitnessed detail. The Experiment 2 means are based on 8 dyad participants and 15 read participants. 
Table 3

Number of Accurate (Out of 35) and Inaccurate Details Reported (Means and Standard Errors)

\begin{tabular}{llllll}
\hline & \multicolumn{4}{c}{ Detail Type } \\
\cline { 2 - 3 } \cline { 5 - 6 } Group & \multicolumn{2}{c}{ Accurate } & & \multicolumn{2}{c}{ Inaccurate } \\
\cline { 2 - 3 } \cline { 5 - 6 } & $M$ & & & $M$ & $S E$ \\
\hline Experiment 1 & & & & \\
$\quad$ Both video & 18.0 & 0.9 & & 1.2 & 0.2 \\
Dyad & 18.9 & 0.7 & & 1.3 & 0.2 \\
Read & 17.9 & 0.6 & 1.8 & 0.2 \\
$\quad$ Control & 18.5 & 0.7 & & 1.9 & 0.3 \\
Experiment 2 & & & & \\
$\quad$ Dyad & 19.2 & 0.7 & 1.3 & 0.2 \\
Read & 18.3 & 0.8 & 0.7 & 0.2 \\
\hline
\end{tabular}

\section{EXPERIMENT 2}

Zaragoza and Koshmider (1989) suggested that "subjects in the typical misinformation experiment are not encouraged to distinguish between what they believe happened in the original event and what they specifically remember seeing" (p. 246). In Experiment 1, participants who originally reported nonwitnessed details often correctly attributed them primarily to the secondary source on a subsequent source-judgment test. It is unclear whether their initial reports resulted because they did not spontaneous engage in source monitoring, because these original source-monitoring attempts failed, or because participants attempted to please the researcher and/or to make themselves appear as accurate as possible. The goal of Experiment 2 was to isolate genuine source-monitoring errors in the memory conformity paradigm, while also providing another test of the potency of misinformation that was obtained in a dyad group relative to that obtained in a read group. To this end, a postwarning instruction explicitly asked participants to not report details that they had acquired from their secondary source unless they also remembered seeing them. We expected these instructions to reduce misinformation effects by encouraging participants to monitor the source and characteristics of their memories more thoroughly (see, e.g., Chambers \& Zaragoza, 2001; Echterhoff et al., 2005; Zaragoza \& Koshmider, 1989).

Prior studies of memory conformity have not explicitly warned participants to not report details obtained from a secondary source unless they also remember them. Instead, participants were simply asked to recall as much as possible about the event (Paterson \& Kemp, 2006a), to think back to what they remembered witnessing (Gabbert et al., 2003), or to respond with only details that they recalled from the video and not to guess (Gabbert et al., 2004; Wright, Gabbert, Memon, \& London, 2008). Experiment 2 tested whether dyads were especially likely to report nonwitnessed details after receiving explicit postwarning instructions.

\section{Method}

Participants. New participants from the same pool that was used in Experiment 1 were randomly assigned to the dyad group (34 participants, 17 pairs) or read group (32 participants, 16 pairs). Two dyad participants were not exposed to either critical detail during collaboration. Three dyad participants reported suspecting that they had viewed a different video from their partner. These 5 participants' data were excluded, leaving 29 dyad group participants. Two read group participants did not complete the main questionnaire, and 1 read group participant's data were lost, leaving 29 read group participants.

Procedure. The procedure followed that of Experiment 1, except that postwarning instructions were added to the main questionnaire and a source-monitoring test was not used. The postwarning instructions explicitly warned participants to report only details that they had personally witnessed. Specifically, participants were told that if they could not recall a detail that was mentioned by their partner during collaboration (dyad group) or read in their partner's report (read group), then they should not report that detail, because it might be incorrect.

\section{Results}

Reporting of nonwitnessed details. Postwarning instructions reduced the rate of nonwitnessed details that were reported relative to Experiment 1 (see Table 1). Moreover, the dyad group was again not significantly more likely than the read group to report at least one nonwitnessed detail $(34 \%$ vs. $28 \%)\left[\chi^{2}(1, N=58)=0.32\right.$, $p=.57]$. Dyad and read group members were exposed to the same number of nonwitnessed details on average $(1.45$ vs. 1.48$)(F<1)$, and the misinformation index was not significantly higher in the dyad group than in the read group $(.29$ vs. .21$)[t(1,56)=0.76, S E=0.11, p=.45]$.

The trend in both of our experiments was for more dyad group members than read group members to show a memory conformity effect. This trend did not reach significance in a combined analysis of Experiments 1 and 2 involving 64 dyad and 68 read participants $(56 \%$ vs. $49 \%)\left[\chi^{2}(1, N=132)=0.79, p=.38\right]$. The trend for the dyad group to show a higher misinformation index than did the read group also did not reach significance in a combined analysis $(.49$ vs. .37$)[t(1,130)=1.51, S E=$ $0.08, p=.13]$.

As is shown in Table 2, participants had higher confidence when reporting witnessed details than when reporting nonwitnessed details (6.2 vs. 5.3$)[F(1,21)=8.45$, $\left.M S_{\mathrm{e}}=0.91\right]$. Unlike in Experiment 1, there was no difference between the dyad and read groups and no interaction (all $F_{\mathrm{s}}<1$ ). Confidence was generally higher than in Experiment 1 , particularly for nonwitnessed details, which follows if participants given postwarning instructions report nonwitnessed details only when they are confident that they saw them in the video.

Memory accuracy. Despite reporting fewer nonwitnessed details, participants reported as many accurate details in Experiment 2 as they did in Experiment 1 (see Table 3), suggesting that the postwarning instructions did not induce a conservative response bias (as in Echterhoff et al., 2005). Unlike in Experiment 1 and in Gabbert et al. (2003) and Gabbert et al. (2007), however, there was a significant positive correlation between the number of accurate details reported and whether a participant reported any nonwitnessed details $\left[r_{\mathrm{pb}}(58)=.28\right]$, suggesting that postwarning instructions may have affected response bias (Wright et al., 2008). Finally, as in Experiment 1, the read and dyad groups reported a similar number of accurate details $[t(1,56)=0.88, S E=1.03, p=.38]$, but the dyad 
group reported more incorrect details $[t(1,56)=2.32$, $S E=0.25]$. In sum, the dyad group was not more likely than the read group to report the critical nonwitnessed details or correct details, but they were more likely to report other kinds of incorrect details.

\section{Discussion}

In Experiment 2, participants were instructed to report a detail only if they remembered seeing it in the video, and not to report it if they remembered it only from the secondary source, because that source might be incorrect. These postwarning instructions sharply reduced the rate of reporting of nonwitnessed details relative to Experiment 1, either by increasing source monitoring or by changing how participants responded in an effort to please the experimenter and/or to be as accurate as possible. The dyad group was, again, not more likely than the read group to report nonwitnessed details, even in a combined analysis of Experiments 1 and 2.

Wright et al. (2008) found that dyads were much less likely to report nonwitnessed details under "strict" test instructions than under "lenient" test instructions, but they were also less likely to report accurate details (i.e., they adopted a more conservative response criterion); however, Wright et al. (2008) did not include a comparison group to determine whether strict instructions particularly affected dyads. We found only one indication that postwarning instructions affected the dyad and read groups differently - namely, the read group reported fewer incorrect details. In contrast, the two groups recalled accurate details at equivalent rates and were also equally confident when reporting witnessed details and when reporting nonwitnessed details.

\section{GENERAL DISCUSSION}

We reexamined the potency of the memory conformity effect - the tendency of co-witnesses to report nonwitnessed details that had been provided by their partner (Wright et al., 2000). Using Gabbert et al.'s (2003) ingenious paradigm, Experiment 1 replicated their main finding: 74\% of the dyad group reported at least one detail that had been obtained solely through collaboration with a partner who had seen a different version of the same event. As detailed below, however, this effect was found to be less robust than was previously suggested, as others have found for the standard misinformation effect (McCloskey \& Zaragoza, 1985; but cf. Loftus et al., 1978). Given that co-witnesses often discuss the event that they witness (Paterson \& Kemp, 2006b; Skagerberg \& Wright, 2008), memory conformity remains an important effect to study, but we have shown that its robustness depends on the choice of memory test, the test instructions, and the comparison conditions. Of course, other factors, such as the distinctiveness of the critical details, will also moderate the size of this effect.

\section{Reevaluating Memory Conformity Using Source Judgments}

Using a postrecall source-judgment task, Experiment 1 revealed that the majority of nonwitnessed critical details that were reported in the dyad, read, and both-video groups were attributed primarily to the secondary source rather than to the original video. This finding accords with Gabbert et al.'s (2003) suspicion that participants who report nonwitnessed critical details "may have been aware that they were using information that they could not remember witnessing themselves" (p. 540). Alternatively, participants may not have spontaneously engaged in source monitoring when completing their original report, or they may have genuinely believed that they had witnessed these details at that time. When later asked to revisit their responses and to adjudicate the primary source of their reports, participants appear to have inspected the source of their memories more carefully (see, e.g., Lindsay \& Johnson, 1989; Marsh \& Hicks, 1998), allowing them to catch some of their earlier errors.

Our source-judgment task differed from variants that other researchers have used (e.g., Gabbert et al., 2007; Zaragoza \& Koshmider, 1989). A common variant asks participants to attribute each response to the actual source, the misinformation source, both, or neither (see, e.g., Lindsay \& Johnson, 1989; Meade \& Roediger, 2002; Zaragoza \& Lane, 1994). Participants often choose the "both" option, leaving the relative contribution of the two sources unknown. Our variant, however, left open the possibility that participants who attributed their responses to the secondary source primarily nonetheless also believed that they had witnessed the details.

Even so, evidence from Gabbert et al. (2007) suggests that dyads may often report nonwitnessed details that they do not remember seeing. In their study, dyads viewed pictures of slightly different arrays of objects, collaborated, and then completed separate memory tests. Each member was then given a postrecall source-judgment task in which they were asked to review their responses and to distinguish between objects that they remembered hearing from their partners but themselves did not remember seeing, objects that they remembered seeing, and those for which they could not recall the source. Of the nonwitnessed objects that they reported, dyad participants attributed $42 \%$ to their dyad partner rather than to having seen those objects. Requiring source judgments can thus effectively reduce the magnitude of the memory conformity effect.

\section{Reevaluating Memory Conformity Using Postwarning Instructions}

Experiment 2 used postwarning instructions to encourage source monitoring, while reducing any pressure that participants felt to report details that they knew that they did not see and/or that they remembered only from the secondary source. Participants were explicitly instructed not to report details that were provided by the secondary source unless they remembered seeing them, and they were told that the secondary source might be incorrect. Under these instructions, dyad and read groups reported about half as many nonwitnessed details as in Experiment 1. By contrast, then, the test instructions that were used in Experiment 1 and in Gabbert et al. (2003) did not effectively guard participants against reporting nonwitnessed details. Those instructions did not encourage source monitoring. 
They may also have allowed participants to assume that they should report details that had been gained from secondary sources, or that they should report such details in order to please the experimenter (i.e., demand characteristics) and/or to be as accurate as possible (i.e., informational demands).

Although a control group was not tested in Experiment 2, the dyad and read groups reported nonwitnessed details even under postwarning instructions. We do not dispute that genuine source-monitoring errors occur in the memory conformity paradigm (see also Gabbert et al., 2007). As acknowledged by Gabbert and colleagues (Gabbert et al., 2003; Gabbert et al., 2004; Gabbert et al., 2007), however, memory conformity can include intentional or unintentional reporting of nonwitnessed details that were not remembered from the event (see, e.g., Zaragoza \& Koshmider, 1989). Postwarning instructions appear to help to reduce these contributors to the memory conformity effect.

\section{Reevaluating Memory Conformity Relative to Comparison Conditions}

Dyads who actively collaborated in completing a report were not significantly more likely to report nonwitnessed details than were pairs of actual participants who completed their reports individually and then read over each other's reports. In contrast, two prior studies provided some evidence that dyads were particularly likely to recall nonwitnessed details (Gabbert et al., 2004; Paterson \& Kemp, 2006a); however, these previous studies did not include a read group in which pairs of actual participants delivered misinformation to each other without engaging in an interactive discussion. Instead, participants in their comparison conditions read a report that had supposedly been written by another participant (Gabbert et al., 2004) or by other people (Paterson \& Kemp, 2006a) who were not present during the experiment. These conditions may have been less compelling and less believable. Paterson and Kemp's (2006a) participants were also asked to agree or disagree with each statement that they heard, which would increase suspicions about that secondary source.

We did not find any consistent differences between our dyad and read groups across Experiments 1 and 2, although other implementations of these conditions might produce some. Importantly, the similarity of these groups' results does not rule out the idea that social factors contribute to misinformation effects. Reading another participant's report might produce as much normative or informational implicit social pressure to report nonwitnessed details as does an interactive discussion. Thus, social influences may have contributed to the memory conformity effect in both groups. Nonetheless, our results show that collaboration between co-witnesses does not always produce an especially large memory conformity effect. The similarity between our dyad and read groups also suggests that modality of misinformation (auditory in the dyad group, visual in the read group) does not always moderate the size of this effect.

In Experiment 1, every participant in the both-video group reported at least one critical detail that was seen only in the second video. In doing so, this group reported more details that had been acquired from a secondary source than did the dyad or read groups, likely because the two video sources were highly similar in semantic content and gist (if different visually) and thus very confusable (see, e.g., Lindsay, 1990). Although a video may not seem a very likely source of secondary information in everyday life, witnesses in our digital age might see a video of an event that is filmed from an angle that is different than the one from which they originally viewed. The potency of a video that is viewed after a live event remains to be evaluated.

\section{Conclusion}

Erroneous eyewitness testimony can have dire consequences, particularly for individuals who are wrongly convicted (see, e.g., Wells et al., 1998). Unless interviewers assert that witnesses must report only firsthand information, witnesses may (intentionally or not) include testimony that is acquired from secondary and potentially inaccurate sources, such as another witness or the media. We therefore echo Zaragoza and Koshmider's (1989) recommendation that researchers distinguish "reports" from "memories" when interpreting misinformation effects, including those involving co-witness interactions. Cowitnesses who report secondhand details do not always believe that they witnessed those details firsthand.

\section{AUTHOR NOTE}

This research was supported by a Discovery Grant from the Natural Sciences and Engineering Research Council of Canada to G.E.B. We thank Fiona Gabbert for supplying her materials. We also thank Keith Lyle, Karen Mitchell, Matt Reysen, and Daniel Wright for their helpful feedback on earlier versions of this article. E.M. is now at Florida State University, and T.A. is at the University of Victoria. Correspondence concerning this article should be addressed to G. E. Bodner, Department of Psychology, University of Calgary, 2500 University Drive NW, Calgary, AB, T2N 1N4 Canada (e-mail: bodner@ucalgary.ca).

\section{REFERENCES}

Ayers, M. S., \& Reder, L. M. (1998). A theoretical review of the misinformation effect: Predictions from an activation-based memory model. Psychonomic Bulletin \& Review, 5, 1-21.

Betz, A. L., Skowronski, J. J., \& Ostrom, T. M. (1996). Shared realities: Social influence and stimulus memory. Social Cognition, 14, 113-140.

Chambers, K. L., \& Zaragoza, M. S. (2001). Intended and unintended effects of explicit warnings on eyewitness suggestibility: Evidence from source identification tests. Memory \& Cognition, 29, 11201129.

Deutsch, M., \& Gerard, H. B. (1955). A study of normative and informational social influences upon individual judgment. Journal of Abnormal \& Social Psychology, 51, 629-636.

Echterhoff, G., Hirst, W., \& Hussy, W. (2005). How eyewitnesses resist misinformation: Social postwarnings and the monitoring of memory characteristics. Memory \& Cognition, 33, 770-782.

Gabbert, F., Memon, A., \& Allan, K. (2003). Memory conformity: Can eyewitnesses influence each other's memories for an event? Applied Cognitive Psychology, 17, 533-543.

Gabbert, F., Memon, A., Allan, K., \& Wright, D. B. (2004). Say it to my face: Examining the effects of socially encountered misinformation. Legal \& Criminological Psychology, 9, 215-227.

Gabbert, F., Memon, A., \& Wright, D. B. (2006). Memory conformity: Disentangling the steps toward influence during a discussion. Psychonomic Bulletin \& Review, 13, 480-485.

Gabbert, F., Memon, A., \& Wright, D. B. (2007). I saw it for longer 
than you: The relationship between perceived encoding duration and memory conformity. Acta Psychologica, 124, 319-331.

Hoffman, H. G., Granhag, P. A., Kwong See, S. T., \& Loftus, E. F. (2001). Social influences on reality-monitoring decisions. Memory \& Cognition, 29, 394-404.

Hope, L., Ost, J., Gabbert, F., Healey, S., \& Lenton, E. (2008). “With a little help from my friends...": The role of co-witness relationship in susceptibility to misinformation. Acta Psychologica, 127, 476-484.

Johnson, M. K., Hashtroudi, S., \& Lindsay, D. S. (1993). Source monitoring. Psychological Bulletin, 114, 3-28.

LindSAY, D. S. (1990). Misleading suggestions can impair eyewitnesses' ability to remember event details. Journal of Experimental Psychology: Learning, Memory, \& Cognition, 16, 1077-1083.

LinDSAY, D. S., \& JoHnson, M. K. (1989). The eyewitness suggestibility effect and memory for source. Memory \& Cognition, 17, 349-358.

Loftus, E. F., Miller, D. G., \& Burns, H. J. (1978). Semantic integration of verbal information into a visual memory. Journal of Experimental Psychology: Human Learning \& Memory, 4, 19-31.

Loftus, E. F., \& PALMer, J. C. (1974). Reconstruction of automobile destruction: An example of the interaction between language and memory. Journal of Verbal Learning \& Verbal Behavior, 13, 585589.

LuUs, C. A. E., \& WelLs, G. L. (1994). The malleability of eyewitness confidence: Co-witness and perseverance effects. Journal of Applied Psychology, 79, 714-723.

Marsh, R. L., \& HicKS, J. L. (1998). Test formats change sourcemonitoring decision processes. Journal of Experimental Psychology: Learning, Memory, \& Cognition, 24, 1137-1151.

McCloskey, M., \& ZaragOZA, M. (1985). Misleading postevent information and memory for events: Arguments and evidence against memory impairment hypotheses. Journal of Experimental Psychology: General, 114, 1-16.

Meade, M. L., \& Roediger, H. L., III (2002). Explorations in the social contagion of memory. Memory \& Cognition, 30, 995-1009.

Ost, J., Ghonouie, H., Cook, L., \& VRIJ, A. (2008). The effects of confederate influence and confidence on the accuracy of crime judgments. Acta Psychologica, 128, 25-32.

Paterson, H. M., \& Kemp, R. I. (2006a). Comparing methods of encountering post-event information: The power of co-witness suggestion. Applied Cognitive Psychology, 20, 1083-1099.
Paterson, H. M., \& Kemp, R. I. (2006b). Co-witnesses talk: A survey of eyewitness discussion. Psychology, Crime \& Law, 12, 181-191.

Pickrell, J. E., Bernstein, D. M., \& Loftus, E. F. (2004). The misinformation effect. In R. F. Pohl (Ed.), Cognitive illusions: A handbook on fallacies and biases in thinking, judgement and memory (pp. 345361). Hove, U.K.: Psychology Press.

REYSEN, M. B. (2003). The effects of social pressure on group recall. Memory \& Cognition, 31, 1163-1168.

REYSEN, M. B. (2005). The effects of conformity on recognition judgements. Memory, 13, 87-94.

Roediger, H. L., III, Meade, M. L., \& Bergman, E. T. (2001). Social contagion of memory. Psychonomic Bulletin \& Review, 8, 365-371.

Schneider, D. M., \& Watkins, M. J. (1996). Response conformity in recognition testing. Psychonomic Bulletin \& Review, 3, 481-485.

Shaw, J. S., III, Garven, S., \& Wood, J. M. (1997). Co-witness information can have immediate effects on eyewitness memory reports. Law \& Human Behaviour, 21, 503-523.

Skagerberg, E. M., \& Wright, D. B. (2008). The prevalence of cowitnesses and co-witness discussions in real eyewitnesses. Psychology, Crime \& Law, 14, 513-521.

Wells, G. L., Small, M., Penrod, S., Malpass, R. S., Fulero, S. M., \& Brimacombe, C. A. E. (1998). Eyewitness identification procedures: Recommendations for lineups and photospreads. Law \& Human Behavior, 22, 603-647.

Wright, D. B., Gabbert, F., Memon, A., \& London, K. (2008). Changing the criterion for memory conformity in free recall and recognition. Memory, 16, 137-148.

Wright, D. B., Self, G., \& Justice, C. (2000). Memory conformity: Exploring misinformation effects when presented by another person. British Journal of Psychology, 91, 189-202.

Zaragoza, M. S., \& Koshmider, J. W., III (1989). Misled subjects may know more than their performance implies. Journal of Experimental Psychology: Learning, Memory, \& Cognition, 15, 246-255.

ZaraGoZA, M. S., \& LANE, S. M. (1994). Source misattributions and the suggestibility of eyewitness memory. Journal of Experimental Psychology: Learning, Memory, \& Cognition, 20, 934-945.

(Manuscript received October 31, 2008; revision accepted for publication June 30, 2009.) 